\title{
A INTERIORIZAÇÃO DA EDUCAÇÃO SUPERIOR NO ESTADO DE SANTA CATARINA: A IDEIA DE UNIVERSIDADE COMO DISCURSO DE DESENVOLVIMENTO
}

\author{
Letícia Carneiro Aguiar ${ }^{\mathrm{i}}$
}

\begin{abstract}
RESUMO
Este artigo tem como objetivo apresentar os fatores que favoreceram o processo de interiorização da educação superior no estado de Santa Catarina na década de 1960. Resultante, sobretudo de estudos documentais, a reflexão que aqui se desenvolve procura demonstrar a relação entre as políticas públicas de expansão da educação superior no período e os interesses regionais privados, e de como ambos estavam sustentados na ideia de universidade como fator preponderante para o desenvolvimento social e econômico local/estadual. A gênese do processo de interiorização ocorreu a partir do surgimento de Faculdades e/ou Escolas superiores isoladas, e que foi se consolidando através da criação de Fundações Educacionais que, em muitos casos, foram criadas pelo poder público municipal, representando na verdade não uma expansão da educação pública, mas, sim, de natureza privada.

Palavras-chave: Educação Superior; Desenvolvimento; Política Educacional.
\end{abstract}

\section{THEINTERIORIZATIONOF HIGHER EDUCATIONIN SANTACATARINA: THE IDEAOFTHE UNIVERSITYAS ASPEECHDEVELOPMENT}

\begin{abstract}
This articleaims to presentthe factors thatfavored theprocess of internalizationof higher educationin the state ofSantaCatarinain the 1960s. Resultingmainlyfromdocumentary studies, reflection thatis developedhereseeks to demonstratethe relationshipbetween public policiesofexpansion of higher educationin the period andprivateregional interests, and howthey were bothsupportedthe idea ofthe universityas a major factorfor the developmentsocial and economiclocal / state. The genesis of theprocess of internalizationoccurredafter the onsetof Colleges and/ orUniversities ofisolated, which was consolidatedthrough the creation ofEducational Foundations, in many cases, were createdby the municipal government, representingnot actuallyan expansionpublic education, butof a private nature.
\end{abstract}

Keywords: Higher Education;Development;Educational Policy.

\section{Introdução}

De natureza bibliográfica e documental, este estudo tem a finalidade de apresentar quais teriam sido os principais fatores que impulsionaram o processo de interiorização das instituições de educação superior (IES) catarinenses na década de 1960. O estudo está inserido numa pesquisa mais ampla, iniciada no ano de 2009 , que tem a finalidade de investigar a gênese das Faculdades de Educação públicas e privadas no estado de Santa Catarina. O que aqui apresentamos é resultado das investigações realizadas até o momento na primeira etapa da pesquisa, a saber, o estudo do processo de interiorização da educação superior, processo este iniciado a partir de 1960, e que utilizou como principais fontes os documentos legais (leis, decretos, pareceres, resoluções), planos e relatórios 
governamentais (Conselho Estadual de Educação - CEE/SC, Secretaria de Estado da Educação - SED/SC) e institucionais (das Instituições de Educação Superior - IES).

Destaca-se esse período da história da educação catarinense haja vista que essa década representou para Santa Catarina um marco no seu processo de modernização econômica, com uma forte intervenção estatal favorecedora da acumulação privada de capital e a adoção do binômio "educação e desenvolvimento" como eixo das políticas públicas. A política educacional catarinense passou a ser pensada como integrante dos planos econômicos globais e, como política pública, voltou-se à atuação na correlação de forças sociais, seguindo determinações do desenvolvimento econômico capitalista.

$\mathrm{O}$ acentuado desenvolvimento econômico em curso produziu o aumento da população urbana e do leque de empregos nos setores secundários e terciários, expressando a necessidade do letramento, do avanço da escolarização. No âmbito estadual, a ampliação de faculdades e cursos superiores expressava uma tendência de organização do ensino superior no Brasil, tendo em vista as novas determinações impostas pelo capitalismo em âmbito estadual e nacional direcionadas à modernização do Estado e à reprodução ampliada do capital. À via educacional cabia o papel de formação de "capital humano". (AGUIAR, 2010).

Destaca-se que em Santa Catarina, até o ano de 1965, existiam apenas duas instituições de ensino superior - a Universidade Federal de Santa Catarina (UFSC) e a Universidade para o Desenvolvimento do Estado de Santa Catarina (UDESC), criadas, respectivamente, no ano de 1960 e 1965, e situadas na capital do estado. A partir desse ano, ocorre um espantoso processo de expansão via interiorização de cursos superiores, sendo que inicialmente isso se deu através do surgimento de faculdades isoladas e que se consolida através da criação de Fundações Educacionais que, em sua maioria, foram criadas pelos poderes públicos municipais, representando, na prática, não uma expansão da educação pública, mas, sim, de caráter privado.

\section{A interiorização da educação superior catarinense}

A mesma ideologia desenvolvimentista que serviu de justificativa para a criação das duas primeiras universidades públicas no Estado de Santa Catarina (AGUIAR, 2008), a UFSC e a UDESC, também influenciou em várias regiões desse Estado os movimentos reivindicatórios pela interiorização do ensino superior. Como o governo estadual de Celso Ramos, eleito em 1960, tardava em cumprir uma promessa de campanha de levar ao interior do Estado o ensino superior, despontaram nas cidades de maior expressão econômica (Blumenau, Joinville, Itajaí, Criciúma, Tubarão, Lages) iniciativas particulares que buscaram atender ao anseio por cursos superiores.

A partir de fins da década de 1960, Santa Catarina vivencia um espantoso processo de expansão e interiorização desse nível de ensino. Inicialmente, esse processo ocorreu através do surgimento de escolas isoladas e que se concretiza a partir desse período, via criação de fundações educacionais, estas criadas, em sua maioria, pelos poderes públicos municipais.

Para Dourado (2001, p.82), o regime jurídico fundacional implantado em Santa Catarina, nos anos 60-70 representou, na verdade, um processo de privatização do público, e como "um modelo de implantação de ensino superior 'municipal', fundacional pago, serviu de modelo para o processo expansionista adotado em Goiás, nos anos 80." Os municípios de Santa Catarina seriam responsáveis por $75 \%$ dos cursos superiores do Estado, o que, segundo esse autor, não indicaria uma expansão do ensino superior público, mas, sim, de caráter privado. Pois, 
as fundações criadas no Estado de Santa Catarina subordinam-se ao Conselho Estadual de Educação, tendo sido implantadas, em sua maioria, pelo poder público municipal, que lhes garantiu o patrimônio original e as subvenções orçamentárias, a despeito de posteriores alterações de fundações de direito público para fundações de direito privado. O que certamente indica um processo de privatização do público no Estado. (DOURADO, 2001, p. 84).

Segundo a Associação Catarinense das Fundações Educacionais (ACAFE), criada em 1974, a partir da iniciativa dos dirigentes das próprias fundações, como instituição responsável pela consolidação do processo de organização, expansão e interiorização do ensino superior fundacional,

criadas pela iniciativa das prefeituras municipais surgiram as IES, mais tarde transformadas em Fundações Educacionais de Direito Privado, prevalentemente. $\mathrm{Na}$ qualidade de poder instituidor, as prefeituras municipais constituíram-se em mantenedoras in terminisdas Fundações Educacionais [...] $\mathrm{O}$ empobrecimento das prefeituras municipais em consequência da política tributária, e a opção das municipalidades - sem esquecer o preceito constitucional - de uma dedicação maior ao ensino de $1^{\circ}$ grau trouxeram, como consequência, uma defasagem progressiva dos recursos financeiros repassados às fundações, ocasionando um processo de privatização progressiva do Ensino Superior Fundacional Catarinense. (ACAFE, 1985, p. 36-37).

O modelo fundacional catarinense efetivou-se através da associação da iniciativa privada com o poder público municipal, assumindo, portanto, uma característica privativista. Coube à esfera privada, a um grupo de pessoas, a criação e instalação do ensino superior no interior do Estado de Santa Catarina.

Esse processo de criação e instalação firmou-se através da parceria entre o poder público e o privado, sendo este o caminho encontrado não só para obter a autorização dos cursos no âmbito estadual, mas também para garantir suporte financeiro à implantação do ensino superior. A feição privada desse nível de ensino ocorre também, "na medida em que o município assume o ônus de financiamento e se ausenta do acompanhamento, da administração e da fiscalização dessas atividades"; bem como pelo fato de que, "embora criado como de natureza pública, esse modelo assume caráter privado (não gratuito), já que os alunos pagam mensalidades escolares." (DOURADO, 2001, p. 91-93).

O sistema fundacional de ensino superior catarinense, tão propalado pelas elites/oligarquias catarinenses como "modelar" para o país (AGUIR, 2008), refletiu o contexto social e político-econômico no qual o próprio sistema educacional nacional tem sido expressão, e cujas políticas engendradas nos anos de 1960 a 1980 não são isoladas, nem autônomas, na medida em que são tecidas numa lógica excludente adotada pelo Estado brasileiro e nela inseridos.

Com o nacional-desenvolvimentismo desencadeia-se um movimento para promover o desenvolvimento econômico priorizando o técnico profissional. A ditadura militar pós-64 aborta os movimentos populistas e toda e qualquer atividade de oposição ao regime. É atribuída ao ensino superior a missão de preparar a força de trabalho, ou seja, o homem para o trabalho necessário ao desenvolvimento proposto pelo novo modelo econômico. A prioridade passa a ser a formação do técnico em nível de $2^{\circ}$ e $3^{\circ}$ graus, sendo que o ensino superior não mais se destina à formação de uma elite liberal, como se 
propagava até meados dos anos de 1960, e nem à ascensão das classes populares, mas à formação do empregado "diplomado" para as grandes empresas nacionais e multinacionais.

Logo, a necessidade de mãodeobra razoavelmente especializada e a procura por vagas serviram de base, no período pós-64, para que o governo brasileiro estimulasse/financiasse a quase completa privatização da educação superior brasileira. Principalmente, no período pós-68, foram concedidas inúmeras facilidades para que se instalasse no país uma vasta rede de estabelecimentos privados de ensino superior. Além de conceder subsídios diretos ou indiretos (isenção de impostos, bolsas de estudos, crédito educativo, facilidades de acesso a créditos bancários estatais, etc.), o Ministério da Educação e Cultura (MEC) deixou na prática de exercer sobre esses estabelecimentos qualquer ação fiscalizadora, comprometendo, assim, seriamente a qualidade do ensino nessas instituições.

Diante da crescente pressão social desenvolvida pós-64, sobretudopelas camadas médias urbanas e pelo movimento estudantil, no ensino superior a privatização foi a base do processo de expansão de vagas. Em resposta a essa pressão, o regime militar elaborou e implantou uma reforma universitária que objetivava atender a uma modernização adaptada ao padrão dependente de desenvolvimento.

Essa ideia de desenvolvimento perpassa todas as esferas de governo e se inculca na consciência da população brasileira. Seus rebatimentos no campo educacional se constituíram a partir da crença generalizada de que a educação compunha a mola mestra do desenvolvimento e, paralelamente, difundia-se a ideia de que a preparação de recursos humanos qualificados se constituía em pré-requisito fundamental do desenvolvimento.

No caso do ensino superior, essa ideia de desenvolvimento e do papel da educação no mesmo norteará os movimentos fundadores das instituições de ensino superior fundacionais de Santa Catarina, movimentos que passaram a reivindicar fortemente a instalação de faculdades, defendendo a tese da interiorização e regionalização do ensino superior.

Vários estudos (D’ÁVILA, 1995; SILVA, 2000; VIEIRA, 2001; SILVEIRA, 2003; VELHO, 2003) têm apontado o papel que a estas instituições de ensino superior estava reservado, tendo em vista que os vários programas propostos pelo governo estadual para o desenvolvimento catarinense exigiam recursos humanos adequadamente preparados, um ensino superior "competente para tratar recursos humanos como capital fundamental da sociedade." (ABREU, 1990, p.33).

Apesar da Lei $\mathrm{n}^{\circ}$ 5.540/68 (Lei da Reforma Universitária) ter estabelecido a exigência de que o ensino superior deveria ser ministrado preferencialmente em universidades e só excepcionalmente em instituições isoladas, na prática o que ocorreu foi exatamente o contrário: a expansão desordenada, com o aval governamental, de instituições de ensino superiores isoladas e privadas. Em 1974, no Brasil, esse tipo de instituição já possuía 786 unidades de ensino.

A Reforma Universitária, para Darcy Ribeiro (1975), "foi mal conduzida", pois ocorreu de forma desorganizada, na medida em que o Conselho Federal de Educação (CFE) dispensou exigências fundamentais e criou inúmeras facilidades para a instalação de IES privadas, perdendo o controle sobre elas, e permitindo o funcionamento de faculdades e universidades em primárias condições e rudimentar estrutura.

Em Santa Catarina, já no ano de 1968, Santos (1968) denunciava certa cumplicidade do poder público municipal e do Conselho Estadual de Educação (CEE) em permitir que instituições de ensino superior funcionassem sem condições adequadas. 
Também, alguns municípios - que têm uma participação no ensino primário bastante reduzida e no ensino médio inteiramente nula - estão a promover a instalação de Escolas Superiores no interior do Estado, sem levar em conta o paradoxo do objetivo, nem muito menos a existência de recursos humanos a financeiros adequados. Nesse sentido, o Conselho Estadual de Educação tem procurado disciplinar o reconhecimento dessas Faculdades, mas o órgão não está estribado num plano global de desenvolvimento do sistema de ensino e sofre as mais variadas pressões para validar a legitimidade das aspirações municipais [grifos do autor]. (SANTOS, 1968, p. 89; grifos do autor).

Germano (1993) aponta que a política educacional do regime militar "privilegiou o topo da pirâmide social" (p. 152), visto que se constituiu num instrumento de conservação da estrutura social de desigualdade, pois seguiu "a estrutura de desigualdade social e regional existente no Brasil", elitizou o ensino superior público e representou um descaso do Estado com a rede pública de primeiro e segundo graus frequentada por alunos que, na sua grande maioria, eram oriundos das classes subalternas. Essa política também imprimiu à educação superior um caráter utilitário, pois estabelecia uma relação direta e imediata com o mercado de trabalho e com a produção.

Como ocorreu com todas as instituições sociais brasileiras, a universidade também foi profundamente marcada por esse período. A análise da política educacional implantada pelo Estado autoritário pós-64 constitui um caso exemplar de como o planejamento ou a determinação da política educacional para o ensino superior, atrelado ao aparelho estatal, procurou de forma exacerbada "produzir indivíduos" em condições de reproduzir as estruturas de um capitalismo dependente.

Essa visível expansão do ensino superior registrada na sociedade pós-64 estava fundamentada no entendimento de uma educação como fator estratégico de desenvolvimento econômico, conferindo a esse nível de ensino uma dimensão prática, imprimindo-lhe uma "racionalidade instrumental" com o propósito de aumentar a produtividade dos sistemas econômicos. A universidade, dentro dessa concepção, ficou atrelada à expansão de um processo de industrialização, que pouco a pouco foi se tornando densamente multinacionalizado, pois àquela deveria formar preferencialmente profissionais vinculados às áreas técnicas, entendidas como próprias das sociedades industriais.

A concepção de educação e de universidade, a partir desse momento, vem transcender uma conceituação meramente econômica, uma vez que procura salientar que o sistema de ensino não apenas cria uma mãodeobra disponível e necessária ao capital, mas ao lado deste ato inculca formas e maneiras de ser, pensar e agir. Nessa perspectiva da educação a serviço dos interesses das elites dominantes, faz sentido pensar e situar o sistema educacional universitário dentro da dinâmica de reprodução ampliada do sistema social global.

O processo educacional inerente à universidade é uma mediação imprescindível na manutenção das relações de dominação, na medida em que o conteúdo das ideias que transmite contribui para obscurecer e mascarar as relações sociais existentes. Inculca padrões e práticas comportamentais, não como principal instituição que cumpre essa função na sociedade, mas como uma das que objetiva reproduzir relações de poder, que na sociedade de classes como a atual, o poder é um poder de classe.

Assim tem-se, por exemplo, a forma como o poder se internalizou no interior da universidade. A partir da política educacional implantada pós-64, seguindo orientações de um poder técnico-burocrata estrangeiro (presentes nos Acordos MEC-USAID, nas 
conclusões do Grupo de Trabalho da Reforma Universitária), a universidade pouco a pouco vai se tornando hierarquizada, rígida e um grande conglomerado de escolas superiores.

Essa situação transformou seus órgãos internos de poder (Reitoria, Conselho Universitário, Departamentos, etc.) em mecanismos de barganha e de defesa de interesses personalísticos e de grupos. Os procedimentos desse poder se situam particularmente nos discursos institucionalizados, no tipo e no modelo de estrutura de poder montado que exclui a maioria dos seus segmentos. Tal modelo de universidade, que representava a consolidação da sua modernização, levou esta instituição a transformar-se num instrumento para o "desenvolvimento e da segurança nacional", preparando mãodeobra necessária e a serviço de um projeto de acumulação capitalista, caracterizado por forte concentração de renda.

É importante destacar que o Estado militar, implantado pós-64 foi

[...] expressão de uma fase do desenvolvimento do capitalismo no Brasil, que ocorre sob a égide dos monopólios e que expressa, sobretudo, os interesses dos conglomerados internacionais, de grandes grupos econômicos nacionais e das empresas estatais, formando um bloco cuja direção é recrutada nas Forças Armadas e que conta com o decidido apoio dos setores tecnocráticos. (GERMANO, 1993, p. 21).

A nova situação econômica e política exige a reorganização da sociedade política e da sociedade civil, de forma que o Estado se torne novamente mediador dos interesses da reprodução ampliada do capital nacional e internacional. Reorganiza-se, portanto, nesse momento, a estrutura de classes, em decorrência dessa reestruturação e redefinição dos aparelhos de Estado.

A política educacional, ela mesma expressão da reordenação das formas de controle social e político, usará o sistema educacional reestruturado para assegurar esse controle. A educação estará novamente a serviço dos interesses econômicos que fizeram necessária sua reformulação. (FREITAG, 1980, p. 77).

As reformas institucionais que vão ocorrer nesse período, notadamente entre 1964-1974, inclusive no campo educacional, contribuíram efetivamente para a reprodução da força de trabalho, à formação dos intelectuais, à disseminação da concepção de mundo dominante necessária à legitimação do sistema político e da sociedade estabelecida, à regulação dos requisitos necessários ao funcionamento do sistema educacional como um todo visando adaptá-lo às necessidades do mercado do trabalho, do desenvolvimento produtivo, etc. (GERMANO, 1993). Nesse período, o governo do Estado de Santa Catarina pensava em atingir o desenvolvimento social a partir do desenvolvimento econômico, e este seria resultado da ação do homem, "pois a expansão econômica não é obtida senão pela ação do homem bem preparado." (ABREU, 1990, p.50).

A ampliação de faculdades e de cursos superiores estava, portanto, expressando uma tendência de organização do ensino superior no Brasil, tendo em vista as novas determinações sociais e econômicas impostas pelo capitalismo em âmbito estadual e nacional, expressas pelas elites locais como a necessária modernização a ser implantada no Estado, onde "as ações governamentais eram colocadas como objetivando o desenvolvimento econômico e social do Estado e o bem-estardo homem catarinense." (AMORIM, 1987, p. 77). À educação caberia a grande tarefa de possibilitar o 
desenvolvimento econômico, à medida que possibilitasse a melhoria da "qualidade dos homens".

Nessa perspectiva, à educação caberia, então, o papel de "formadora de mãodeobra, isto é, educação como recurso para a produção", sendo seu dever o de formar o homem como força produtiva eficaz. Essa concepção educacional, "além de se preocupar com o preparo de recursos humanos necessários ao desenvolvimento, [...], trata os indivíduos como iguais potencialmente, cujas habilidades serão desenvolvidas pela escola". Desse modo, a via educacional prepara o capital humano "para acelerar o desenvolvimento e é vista como um dos canais mais importantes para a ascensão social, como se não existissem diferenças fundamentais resultantes da sociedade de classes". (AMORIM, 1987, p. 51-53).

Era uma concepção de educação fundamentada na Teoria do Capital Humano (TCH), na ideologia da igualdade de oportunidades e das aptidões naturais, de natureza profundamente economicista e dissimuladora das contradições sociais (FRIGOTTO, 1995). Uma concepção caracterizada por Saviani (1985) como tecnicista educacional.

Foi referenciada nessa concepção da função social da educação que as instituições de ensino superior, e no seu interior seus cursos de graduação, proliferaram-se em todas as regiões do estado catarinense.

Para Hawerroth (1999), foram os setores mais dinâmicos da sociedade, principalmente empresarial de diversos ramos de atividades econômicas, que passaram a defender e reivindicar a imediata instalação de instituições de ensino superior em suas regiões, impulsionados também pelas políticas estatais que fizeram desse nível de ensino, na década de 60, um dos pontos básicos da infraestrutura buscada para o alcance da modernização. Para esse autor, lideranças políticas locais acreditavam que o ensino superior municipal poderia ser um elemento catalisador do desenvolvimento regional.

Segundo Amorim (1987), essas reivindicações estavam respaldadas pela crescente demanda por ensino superior, no período de 1960-1970, tendo em vista o crescimento vertiginoso na matrícula do ensino médio colegial - de 572\% em Santa Catarina, e com o número de egressos desse nível de ensino - subindo de 1.005 em 1962 para 4.746 em 1969. (SANTA CATARINA, 1971, p. 158-200).

Dados da Secretaria de Estado da Educação do ano de 1971 permitem inferir que a interiorização do ensino superior também foi propulsionada pelo fato de que os alunos matriculados no ensino médio (27.407 alunos) estariam relativamente bem distribuídos pelas doze Coordenadorias Regionais de Educação (CRES). Entretanto, a expansão via interiorização do ensino superior não representou, necessariamente, uma democratização do acesso a esse nível de ensino, pois o número de egressos do ensino médio e, portanto, com possibilidades de ingressar numa faculdade, ainda era restrito.

O Plano Setorial de Educação I - 1973-1976 - de Santa Catarina, ao tratar da articulação da escola de nível médio com o ensino superior, acabava revelando duas situações que contribuem para desmistificar a expansão do ensino privado como via de democratização de oportunidades educacionais, e como via necessária ao desenvolvimento regional. Esse documento é enfático em afirmar que

o ensino de nível médio, sem oferecer condições de terminalidade, pressiona o surgimento de várias unidades de Ensino Superior pelo Estado e deflagra o processo de interiorização do Ensino Superior, recebendo o apoio de governos municipais ou associações municipais, as quais, até então, pouco ou nada contribuem para o desenvolvimento do ensino médio em seus municípios e regiões. (SANTA CATARINA, 1972, p. 147). 
O Plano Setorial de Educação II apresentava dados do quanto o acesso ao ensino superior, pelos concluintes do ensino médio, era uma possibilidade remota para a grande parcela da população jovem catarinense.

Matrículas do Ensino Médio e Superior Santa Catarina - 1968 e 1971

\begin{tabular}{|c|c|c|}
\hline Ano & Ensino médio & Ensino superior \\
\hline 1968 & 19.580 & 4.140 \\
\hline 1971 & 35.986 & 5.712 \\
\hline
\end{tabular}

Fonte: Santa Catarina, 1972, p. 147.

Na realidade, não seria de fato de interesse das elites catarinenses oportunizarem a democratização do acesso ao ensino superior, pois era nítido o objetivo da classe dirigente em relação a esse nível de ensino quando proclama no Plano Estadual de Educação - 19691980 "que os cursos universitários sejam oferecidos aos indivíduos mais bem dotados intelectualmente", indicando também a sua preocupação com a formação de uma elite intelectual a serviço do "Estado-de-classe".

Há que se considerar, contudo, que apesar da significativa ampliação da demanda, também considerável número de jovens catarinenses permaneceu fora da escola de segundo graunesse período. No ano de 1984, por exemplo, dos 498.070 jovens de 15 a 19 anos apenas 70.104 (14\%) frequentava o ensino de segundo grau no Estado. Acrescente-se a esses dados o número de evadidos e reprovados nesse grau de ensino, na casa dos $51,71 \%$, e conclui-se o quanto o término do segundo grau e posterior acesso ao terceiro grau continuaram apenas como uma aspiração para significativa parcela de jovens catarinenses. (AURAS, 1993, p. 108).

Outro elemento indicador de que o sistema educacional catarinense, apesar do discurso em contrário, apresentava um caráter antidemocrático e indicador da agravante situação na qual se encontrava o ensino catarinense era a questão da possibilidade de permanência na escola para milhares de crianças e jovens catarinenses: em 1971, de cada 1.000 alunos que ingressavam no ensino de primeiro grau, apenas 58 chegavam ao ensino de terceiro grau em 1982.

As instituições de ensino superior fundacionais foram gradativamente aparecendo no cenário catarinense. No período de 1960 a 1980, surgiram no Estado 17 fundações educacionais, perfazendo um total de 19 instituições de ensino superior, se considerar as duas universidades públicas (estadual e federal) criadas no início desse período.

As Fundações Educacionais, criadas em sua maioria em fins da década de 1960 e início da década de 1970, foram pensadas para responder a exigências das realidades regionais - das suas microrregiões, sendo projetadas, inicialmente, para atender às demandas de uma realidade caracterizada como geoeducacional.

Para Vahl (1980), a expansão desordenada do ensino superior e a falta de consciência social das instituições, sem comprometimento maior com o desenvolvimento do país, atingiram momentos críticos que chegou a ocorrer a proibição temporária para autorização de novos cursos superiores. Apesar de terem sido pensadas para representarem um "peso significativo" no desenvolvimento regional, a maioria dessas instituições teve 
pouca inserção nessas realidades regionais, pois acometidas que foram pelas mesmas contradições vividas pela universidade brasileira em geral. Segundo Martins (falta a referência (1983, p.21), foram contradições como:

[...] a necessidade de reproduzir uma cultura e criar outra; a contradição entre as necessidades dos alunos e as necessidades impostas pela instituição; a dicotomia trabalho manual e trabalho intelectual; a contradição entre teoria e prática, entre cultura burguesa e cultura popular; a contradição entre ideologia imposta e a ideologia das camadas que ingressam na instituição [...].

O regime jurídico e as condições pedagógicas regulamentadas, na época exigida pelo MEC, longe de assegurarem condições mínimas de desempenho das atividades acadêmicas nessas instituições, estimularam as inversões privadas e a lucratividade no ensino (DOURADO, 2001). As facilidades encontradas no CFE para a criação de cursos e estabelecimentos de ensino superior favoreceram essas inversões.

Tais facilidades também encontraram ressonância nos Conselhos Estaduais de Educação, pois no caso de Santa Catarina, segundo determinava a legislação que possibilitou a criação desse Conselho, a Lei no 3.030, de 15 de maio de 1962, em seu artigo 22, entre as atribuições do CEE, competia-lhe "fixar normas para autorização, reconhecimento e inspeção dos estabelecimentos de ensino em todos os níveis", bem como "autorizar o funcionamento e fiscalizar os estabelecimentos de isolados de ensino superior, estaduais e municipais." (referência?)

Nesse sentido, é necessário acentuar que muitos cursos criados nessas instituições superiores foram justamente aqueles que, regra geral, seriam menos dispendiosos, tais como: Pedagogia, Letras, Estudos Sociais, Ciências Contábeis, Administração, etc., predominando os cursos formadores de profissionais para atuar no ensino de primeiro e segundo graus. (AURAS, 1993).

[...] dos 105 cursos oferecidos atualmente [1985] pelas instituições fundacionais de Santa Catarina, 58 são licenciaturas. Destes, 51 cursos foram autorizados no período de 1968/74, quando foram autorizados 71 cursos dos 105 existentes atualmente. (AMORIM, 1987, p. 80).

Freitag (1980, p. 68-69) aponta que para que o setor privado realmente pudesse expandir-se e explorar a educação como negócio, ele se apoderou daqueles cursos que exigiam um mínimo de equipamento, pouca qualificação do professor, mas que tivesse grande procura. Esse setor, afirma a autora, interessado em manter e ampliar esse negócio, também adotou a estratégia de "adaptar sua oferta de custos à demanda", isto é, a preços acessíveis aos mais pobres. Evidentemente, "o produto vendido não podia ser da mesma qualidade que o consumido gratuitamente pelas classes privilegiadas que ocupa em sua maioria a rede oficial.” (FREITAG, 1980, p. 115).

O setor privado correspondeu, assim, tanto aos interesses do Estado como, aparentemente, aos interesses daqueles vestibulandos rejeitados pela rede oficial. Explorando a motivação educacional e o desejo de ascensão das classes subalternas, os estabelecimentos de ensino particulares passaram a fazer da educação um negócio. (FREITAG, 1980, p. 113; grifo do autor). 
O Plano Setorial de Educação I do Estado de Santa Catarina (1973-1976), quando trata da questão do ensino superior, divulgava dados que corroboram algumas das afirmações de Freitag (1980). Com relação às "oportunidades" educacionais nesse nível de ensino, o Plano faz menção ao fato de que, no ano de 1971, houve um montante de 5.712 alunos matriculados, correspondendo a um crescimento de $72,8 \%$ em relação ao ano de 1967. Esse crescimento, destaca o Plano, "foi mais significativo na rede municipal, em decorrência da criação de unidades isoladas de ensino superior mantidas pelos municípios no interior do Estado." (SANTA CATARINA, 1972, p. 215). Em 1976, havia no Estado de Santa Catarina cerca de 22.000 universitários, sendo que $70 \%$ estavam matriculados no sistema fundacional. (SANTA CATARINA, 1977, p. 93).

É sabido que a verdadeira manutenção dessas instituições, via de regra, sempre ocorreu através de mensalidades pagas pelos alunos. (MORETTI, 1984). Mas, muitas instituições foram também subvencionadas com dinheiro público. É necessário destacar que a própria Constituição de 1967 reforça, em seu artigo 168, § 2º o que a Lei de Diretrizes e Bases da Educação (LDB) de 1961 já havia estabelecido: fortalecer o ensino particular assegurando-lhe explicitamente "ajuda técnica e financeira do governo, inclusive bolsas de estudos".

Para se dimensionar o envolvimento do Estado catarinense com o sistema fundacional, principalmente na década de 1970, destaca-se que o Plano Setorial de Educação II apresentava um único objetivo geral, em relação ao ensino superior: "fortalecer e expandir coordenadamente o Sistema Fundacional, elevando sua eficiência." (SANTA CATARINA, 1977, p. 95).

Observa-se, assim, que houve uma prática de incentivos governamentais para a estruturação do ensino superior no Estado. Mas, com o crescente descompromisso dos poderes públicos para com a educação, e a concentração cada vez maior de recursos em nível federal, os estudantes dessas fundações é que passaram a arcar cada vez mais com os seus custos de manutenção. $O$ Estado somente não abriu mão do controle político.

Foi nesse contexto sociopolítico que surgiram no interior do estado de Santa Catarina, na década de 1960, as primeiras Faculdades voltadas à formação de professores para atuarem na escola ginasial e média do sistema educacional catarinense. Veja-se, então, como se caracterizou o surgimento dessas instituições, e qual foi o discurso institucional apresentado para justificar a criação de cursos de licenciatura no interior das mesmas.

\section{A criação das primeiras Fundações Educacionais no interior do estado de Santa Catarina}

A primeira Fundação Educacional a surgir no interior do estado catarinense foi a Fundação de Ensino do Polo Geoeducacional do Vale do Itajaí - FEPEVI, queera uma instituição de ensino superior, com sede na cidade de Itajaí, criada no ano de 1970, a partir da agregação de duas escolas superiores isoladas. Entretanto, o ensino superior nessa cidade, iniciou suas atividades alguns anos antes da criação da FEPEVI.

O ensino superior na cidade de Itajaí inicia-se com a criação, em 1962, da Sociedade Itajaiense de Ensino Superior (SIES), uma entidade de natureza privada. Mas, somente no ano de 1964 seu estatuto foi registrado em cartório e foram criadas as Faculdades que a integraram: Faculdades de Ciências Jurídicas e Sociais do Vale do Itajaí e Faculdade de Filosofia, Ciências e Letras do Vale do Itajaí. Inicialmente essas faculdades funcionavam na "clandestinidade", pois não tinham autorização de funcionamento do CEE. 
Em 22 de setembro de 1964, as Faculdades são oficializadas como estabelecimentos municipais de ensino superior, através da Lei municipal $n^{\circ}$ 599/64 e Decreto 48A. A ideia de criação de cursos superiores nessa cidade "nasceu da ideia de um grupo de cidadãos itajaienses que sentiram a necessidade da implantação de escolas de nível superior em Itajaí. Até então os filhos da terra que quisessem prosseguir seus estudos, teriam que se transferir para outras capitais." (FFCL DO VALE DO ITAJAÍ, 1986, p. 6).

D'Avila (1995) afirma que os "filhos da terra", na realidade, representavam parcelas da classe média local, que, mobilizados através do movimento estudantil secundarista - União dos Estudantes Secundários de Itajaí, exerceram significativa pressão sobre o poder público local para a criação de escolas superiores, mobilizando também outros setores da sociedade itajaiense. Lideranças políticas e empresariais, professores, lideranças estudantis difundiam a ideia da educação como forma de elevação cultural e social da cidade de Itajaí, o que para eles seria possibilitado através da criação de faculdades.

Em 1968, a SIES é transformada em Autarquia Municipal de Educação e Cultura (AMECCI), pela Lei Municipal no 892/68, sendo transformada em 1970 na Fundação de Ensino do Polo Geoeducacional do Vale do Itajaí (FEPEVI), pela Lei Municipal $\mathrm{n}^{\circ}$ 1.047/70. No ano de 1986, através da Portaria Ministerial $\mathrm{n}^{\mathbf{0}}$ 051/89, ocorre o reconhecimento da Universidade do Vale do Itajaí (UNIVALI), e nesse mesmo ano, pela Lei Municipal $\mathrm{n}^{\circ}$ 2.515, de 19 de outubro de 1989, a FEPEVI é transformada em Fundação Universidade do Vale Itajaí (FUVALI).

Segundo D'Avila (1995), a SIES buscava o poder público municipal como suporte, procurando com isso "aparentemente publicizar a educação de terceiro grau, mas em verdade como instrumento dos seus interesses privatistas", iniciando aí uma cumplicidade entre o público e o privado, "em que o município fazia de conta que os cursos superiores eram privados e a SIES, por sua vez, fazia de conta que eles eram municipais."

Em 1968, desmantela-se essa cumplicidade, quando a prefeitura vê-se na obrigação de assumir a entidade, sem ter condições financeiras para fazê-lo. Buscou, então, apoio do governo estadual e de municípios da região para compartilhar a responsabilidade pela manutenção da entidade. (D’AVILA, 1995, p. 89). Mas, era início dos anos 70, e os governos assimilavam cada vez mais a ideia de refazer o ensino superior brasileiro nos moldes do ensino norte-americano, um modelo de privatização e de introdução de uma mentalidade empresarial dentro das IES.

Por isso, a criação da FEPEVI significou a "refundação" do ensino superior no Vale do Itajaí, "na medida em que o modelo fundacional, ou seja, ensino público pago diferia do ensino privado originalmente intentado pela SIES e do ensino público gratuito." (DÁVILA, 1995, p.90). Logo, a criação da FEPEVI representou uma medida "salvadora" que se ajustou perfeitamente ao discurso pós-64, segundo o qual a gratuidade da educação para todos era uma medida "antidemocrática". Representou, assim, a concretização da política de privatizar tanto quanto possível o ensino superior público, dando-lhe corte empresarial e adequado às leis de mercado.

No ano de 1967, na cidade de Blumenau, foi criada a segunda instituição de caráter fundacional no interior de Santa Catarina, a Fundação Educacional da Região de Blumenau-FURB, sendo que seu surgimento também resultou a partir da agregação de algumas Escolas Superiores isoladas.

A história dessa universidade envolveu um intenso trabalho de mobilização da comunidade regional em prol da criação do ensino superior na região, iniciando com base em solicitações para a implantação de unidades de ensino superior no Vale do Itajaí, 
através de movimentos da opinião pública já a partir de 1953. Essas mobilizações partiram da Câmara de Vereadores do município de Blumenau, da União Blumenauense de Estudantes e de Clubes de Serviços.

Essas instituições da sociedade civil mobilizaram a comunidade regional em torno da idealização da criação de uma universidade, que teria o papel de "contribuir para o desenvolvimento da região, rompendo com o monopólio do ensino superior na capital do Estado". Foi um movimento que, sem apoio político e técnico da capital do Estado, buscou auxílio em outras universidades de outros Estados, como a Universidade de São Paulo (USP) e a Universidade de Santa Maria (UFSM).

Durante toda uma década, membros da comunidade regional do Vale do Itajaí desencadearam debates com o objetivo de sensibilizar o poder público estadual e federal em torno de suas reivindicações com vistas à interiorização do ensino superior em Santa Catarina. Diversas tentativas realizadas na área política acabaram determinando amplos debates na Assembléia Legislativa do Estado, o que resultou na criação, em 1957, da Faculdade de Engenharia de Joinville, que em 1965 foi integrada à UDESC.

Em nível local, a mobilização comunitária resultou na criação da primeira unidade de ensino superior no interior do Estado - a Faculdade de Ciências Econômicas de Blumenau, em 5 de março de 1964, através da Lei Municipal ${ }^{\circ} 1.233$. Inicialmente, as aulas funcionavam nas dependências de uma escola primária e, a partir de 1965, funcionava numa escola básica onde a própria FURB acabou se instalando quando da sua criação.

$\mathrm{Na}$ data de 20 de dezembro de 1967, a Lei Municipal $\mathrm{n}^{\circ} 1.458$ instituiu a Fundação Universitária de Blumenau. Com base na mesma lei, são criadas a Faculdade de Filosofia, Ciências e Letras de Blumenau e a Faculdade de Ciências Jurídicas de Blumenau. E a partir de 1968, novamente a comunidade mobiliza-se em prol da construção da sede própria da instituição, que ocorreu apenas em 1969.

Pela lei que a instituiu, a FURB foi definida como "[...] entidade de ensino técnica e cultural", [...], sendo seu objetivo "criar e manter institutos de ensino superior de estudo e pesquisa”. O Decreto Municipal n ${ }^{\circ}$ 802, de 27 de dezembro de 1967, que aprovou o Estatuto da universidade ampliou seus objetivos, estabelecendo-os como sendo, entre outros: "a) promover pesquisa e o desenvolvimento das ciências, letras e artes; b) formar profissionais técnico-científicos, liberais e do magistério para as altas funções da vida pública; [...]; h) atuar no processo de desenvolvimento do país." (FURB, 1968).

Destaca-se que em 5 de outubro de 1968, ocorre, na cidade de Ibirama, o I Encontro Intermunicipal Pró-Ensino Superior no Vale do Itajaí, que teve como principal objetivo realizar o "assentamento definitivo das bases para o surgimento da Universidade Regional". A FURB considerou que esse evento revestiu-se de grande importância, pois "nessa ocasião, foi consolidado o apoio do setor político em torno do ideal universitário, bem como os objetivos primeiros da iminente Universidade que visava à integração de todos os municípios da região, o que foi assegurado com êxito." (FURB, 1968).Integravam a estrutura patrimonial da FURB: a Fundação Universitária de Blumenau, Faculdade de Ciências Jurídicas de Blumenau, Faculdade de Ciências Econômicas de Blumenau, Faculdade de Filosofia, Ciências e Letras de Blumenau, Hospital Santo Antonio, Hospital Infantil e Museu Dr. Fritz Muller (estes três últimos foram devolvidos ao patrimônio do município anos depois).

A Lei Municipal no 2.016, de 22 de julho de 1974, alterou o nome da Fundação Universitária de Blumenau para Fundação Educacional da Região de Blumenau (FURB). Em 13 de fevereiro de 1986, a Portaria Ministerial $\mathrm{n}^{\circ} 117$ concede reconhecimento e credenciamento à FURB como universidade. E a partir de 21 de março de 1995, a Lei 
Complementar Municipal $\mathrm{n}^{\circ}$ 80, determina que, desde então, a Universidade Regional de Blumenau seja considerada como uma instituição de ensino superior criada e mantida pela Fundação Universidade Regional de Blumenau (FURB), sua mantenedora. A FURB é incluída como órgão autônomo na estrutura administrativa do Poder Executivo Municipal, uma instituição oficial de direito público, com autonomia didático-científica, de gestão financeira e patrimonial.

Em 1967, na região sul surgiu a primeira Fundação Educacional dessa região catarinense, a Fundação Educacional do Sul de Santa Catarina (FESSC), sediada na cidade de Tubarão, pela Lei Municipal no 443/67, de 18 de outubro de 1967, em substituição ao Instituto Municipal de Ensino Superior (IMES). Como as demais instituições de ensino superior, sua gênese encontra-se numa instituição isolada de ensino superior.

O IMES surgiu a partir da iniciativa de um grupo de particulares que, liderados por Osvaldo Della Giustina, na época radialista e professor, após conhecerem a experiência de criação da Faculdade de Ciências Econômicas de Blumenau, encaminham um relatório da viagem ao Prefeito de Tubarão que o incube de liderar a implantação da Faculdade de Ciências Econômicas de Tubarão. Em decorrência, em 25 de novembro de 1964, pela Lei Municipal $\mathrm{n}^{\circ} 353$ foi criada a Faculdade de Ciências Econômicas com o curso de Economia. Posteriormente, em 10 de dezembro de 1964, pela Lei Municipal $\mathrm{n}^{\circ}$ 355, foi criado o IMES, uma Autarquia Municipal que manteria a Faculdade de Ciências Econômicas. Essa faculdade foi a primeira do interior do estado a ser reconhecida pelo Governo Federal.

Com a instituição da FESSC, a partir de 1967, ampliam-se suas atividades na área do ensino, da pesquisa e desenvolvimento e da educação permanente. No ano de 1986, esta fundação educacional foi transformada em universidade, através da Portaria Ministerial $\mathrm{n}^{\circ}$ 028, de 27 de janeiro, passando a denominar-se de Universidade do Sul de Santa Catarina (UNISUL), cuja mantenedora passa a ser a Fundação Universidade do Sul de Santa Catarina.

A criação da FESSC teve como finalidade:

1) Criar, integrar ou agregar, organizar e manter escolas especificamente de nível superior e de nível médio, estas de cunho profissional, de acordo com as exigências do mercado de trabalho da Região, do estado e do País;

2) Promover: a) cursos de formação, treinamento e especialização, para graduados ou não; b) cursos de pós-graduação; estudos e pesquisas, relacionados com o desenvolvimento econômico e social da Região e do Estado, por conta própria, de terceiros, ou em cooperação com entidades públicas ou particulares; c) conferências, debates, seminários, bem como a divulgação de estudos relacionados com a problemática da economia em geral e especificamente da Região Sul de Santa Catarina;

3) Adotar medidas cabíveis para organização e implantação da futura Universidade do Sul de Santa Catarina. (FESSC, 1967).

Também na região sul catarinense, no ano de 1968, foi instituída a Fundação Educacional de Criciúma (FUCRI), sediada na cidade de Criciúma, pela Lei Municipal $\mathrm{n}^{\circ}$ 697, de 22 de junho de 1968, inicialmente como o nome de Fundação Universitária de Criciúma que, por determinação do CFE, teve seu nome alterado em 1974 para Fundação Educacional de Criciúma. Adquiriu o reconhecimento como universidade em 1997, passando a ser denominada de Universidade do Extremo Sul Catarinense (UNESC).

A FUCRI foi criada com a finalidade de: 
a) organizar e manter estabelecimentos de ensino, de grau universitário;

b) promover a divulgação de assuntos de natureza técnica, científica e cultural;

c) colaborar, reciprocamente, com entidades públicas e particulares de quaisquer natureza, entidades religiosas e associações em geral, objetivando a implantação, expansão e o aprimoramento do ensino superior;

d) contratar estudos e projetos, visando ao desenvolvimento tecnológico, científico e cultural;

e) realizar e contratar estudos que possibilitem definir as necessidades do meio social no setor do ensino superior. (PREFEITURA MUNICIPAL DE CRICIÚMA, 1968).

Essa instituição de ensino superior emergiu de um movimento comunitário regional que culminou com a realização do I $^{\circ}$ Seminário de Estudos Pró Implantação do Ensino Superior na Região Sul Catarinense, realizado nos dias 22 e 23 de julho de 1968, promovido pela Prefeitura Municipal de Criciúma e a Câmara Júnior de Criciúma. Participaram do evento lideranças políticas, educadores, intelectuais, magistrados, lideranças comunitárias, sociedade civil organizada e imprensa. (PREFEITURA MUNICIPAL DE CRICIÚMA, 1968). Vários temas foram objeto de debates neste Seminário. Foram discutidas questões como: a interiorização do ensino universitário, as faculdades que deveriam ser implantadas de imediato na região, financiamento para instalação das faculdades, as vantagens do sistema fundacional.

Em suas conclusões, os participantes desse evento regional expressam seu alinhamento com o discurso nacional e estadual em relação ao ensino superior, indicando as bases sobre as quais a classe política, empresarial e intelectual regional pretendia criar esse nível de ensino na região: a ideia de universidade como elemento necessariamente gerador do desenvolvimento e integração regional, estruturada com base nos princípios da racionalidade, eficiência e produtividade, portanto, em condições técnicas e financeiras que possibilitasse "rentabilidade", nos moldes da empresa privada.

1 A interiorização do Ensino Superior justifica-se desde que vise à integração e ao desenvolvimento regional.

2 Para que possa haver a interiorização, deverá ser levada em conta, também, a existência de condições técnicas e financeiras para que o Ensino Superior se concretize em termos de rentabilidade. (PREFEITURA MUNICIPAL DE CRICIÚMA, 1968).

Possivelmente esse movimento político que desencadeou a organização do Seminário atendia aos interesses dos grupos econômicos que viam na educação superior um locus para a formação de mãodeobra mais especializada voltada às atividades econômicas da região - indústria de mineração, carboquímica, cerâmica, etc. Pode-se visualizar tal perspectiva na justificativa da criação da primeira Faculdade de Educação no sul do estado de Santa Catarina - a Faculdade de Ciências da Educação de Criciúma (FACIECRI).

Teve por finalidade primeira a Faculdade de Ciências da Educação de Criciúma, integrar o homem na sociedade, habilitá-la no plano econômico, como agentes de produções e de consumo, sem deixar de despertar nele a 
consciência do valor do seu trabalho, de seus direitos e deveres, enfim de seu valor humano. (UNESC, 1993).

\section{Considerações finais}

Enfim, pode-se afirmar que vários fatores de ordem social, política e econômica teriam impulsionado a criação e a crescente proliferação da educação superior catarinense. Alguns fatores contribuíram para favorecer o surgimento desses movimentos, tais como: o crescimento vertiginoso na matrícula do ensino médio colegial (572\%) e o aumento do seu número de egressos, provocando uma ampliação da demanda por cursos superiores; as necessidades postas pelo processo de diversificação dos ramos de atividades econômicas, cujo empresariado passou a defender a imediata instalação de instituições de ensino superior em suas regiões, impulsionados também pelas políticas estatais que fizeram desse nível de ensino um dos pontos básicos da infraestrutura buscada para o alcance da modernização; a ideia de prestígio, poder, ascensão social e profissional via diploma de ensino superior para as classes médias; a necessidade de oportunizar às novas gerações "permanecer atuando na cidade, gerando riquezas e aperfeiçoando sua força de trabalho". (VIEIRA, 2001, p.43).

Assim, o processo de interiorização da educação superior em Santa Catarina ocorreu num determinado contexto econômico e político no qual à educação foi atribuído um papel preponderante na modernização socioeconômica do Estado, vinculada à ideologia de modernização capitalista e de industrialização da sociedade catarinense e da necessidade de afirmação das forças sociais capitalistas hegemônicas. (AGUIAR, 2008).

As Fundações educacionais foram criadas e seus cursos superiores são projetados com base no discurso de que o ensino superior seria um instrumento para $o$ desenvolvimento. E são vários argumentos institucionais utilizados para justificar a criação de cursos superiores, desde questões que denotam uma preocupação com a continuidade dos estudos dos jovens cidadãos da cidade, ascensão social, até a melhoria do desempenho profissional.

Propunham-se as Fundações educacionais, através de suas Faculdades ou Escolas superiores, reterem "os filhos da terra", e com isso sustentar o desenvolvimento da cidade, pois nada melhor que uma universidade para consolidar e dar suporte ao desenvolvimento. $\mathrm{O}$ ensino superior oportunizaria à força jovem permanecer atuando na cidade, gerando riquezas e aperfeiçoando sua força de trabalho. Demonstravam as instituições, desse modo, sua preocupação com o aprimoramento da juventude estudantil e, provavelmente, por detrás desse discurso, pela oportunidade que através do ensino superior teria a classe média de promover sua ascensão social. Logo, mobilidade social e realização pessoal seriam vistos como decorrentes do progresso econômico local e regional.

Tal discurso, considerando o quadro profundamente antagônico, em termos de condições de vida (que uma sociedade de classes apresenta), uma "escola para todos" pautada nos padrões de uma minoria só poderia mostrar-se implacável com as diferenças dos que a ela ascendem. Tratamento igual para todos, embora pareça coerente com o princípio de "todos são iguais perante a lei", tem-se mostrado bastante eficaz, em sociedades como a brasileira, na recolocação definitiva das diferenças sociais.

As Faculdades com seus cursos superiores constituiriam, assim, no discurso institucional, a mola mestra do desenvolvimento local, regional e estadual. Possivelmente, dessa forma, contribuíram esses cursos para a difusão de uma ideologia da classe dominante que atrelava a educação ao desenvolvimento econômico e social. Ideologia esta pautada numa perspectiva economicista de causalidade, associada a um economicismo 
burguês que afirmava ser a educação do "povo" a responsável pelo desenvolvimento econômico. Tal concepção economicista de educação ignora o fato de que a desigualdade social existente na sociedade não se explica exclusivamente por uma distribuição desigual do conhecimento, mas sim pelas próprias características do modelo econômico capitalista que tende a concentrar, de forma contínua, a riqueza historicamente produzida.

Segundo a ótica liberal-burguesa, o sistema educacional teria um papel de gerar oportunidades de ascensão social, garantindo a "igualdade de oportunidades". Tal discurso não se sustenta, pois o desenvolvimento de uma nação se dá por um conjunto de fatores, e a educação escolar não pode ser encarada como panaceia para todos os males. Não bastaria apenas o investimento na formação e qualificação da força de trabalho, para haver um maior acesso à riqueza produzida por parte da população. A possibilidade de distribuição desta riqueza depende, exclusivamente, de uma mudança das relações de poder e de uma modificação radical do sistema de produção. Assim, o discurso de aliar educação e desenvolvimento tem seu papel ideológico. Ele cumpre a função de livrar o sistema capitalista de maiores críticas.

\section{Referências}

ABREU, Alcides. Ainda é tempo. Universidade do Estado de Santa Catarina. Idealização e construção da história: UDESC 1965-1990. Florianópolis, 1990.

ASSOCIAÇÃO CATARINENSE DAS FUNDAÇÕES EDUCACIONAIS. ACAFE. Panorama do ensino superior fundacional do Estado de Santa Catarina. Florianópolis, 1985.

AGUIAR, Letícia Carneiro. Política educacional e a criação do curso de Pedagogia em Santa Catarina. Palhoça: Ed. da Unisul, 2008.

Um legado do século XX para a política educacional do século XXI: a Teoria do Capital Humano. RevistaHistedbrOnline, Campinas,n. 40, p. 126-144, dez. 2010.

AMORIM, Maria das Dores Daros de. Ensino Superior Fundacional: por que e para quê?Cadernos do CED. Florianópolis: UFSC/CED, n.9, 1987, p. 71-89.

AURAS, Gladys Mary Teive. A formação do professor das séries iniciais do ensino de $1^{\circ}$ grau no âmbito da política de modernização econômica no Estado de Santa Catarina. 1993. 145 f. Dissertação (Mestrado em Educação) - Universidade Federal de Santa Catarina, Florianópolis, 1993.

DÁVILA, Edson. O público e o privado na Fundação do Ensino Superior em Itajaí. 1995. Dissertação (Mestrado em História) - Universidade Federal de Santa Catarina, Florianópolis, 1995.

DOURADO, Luiz Fernandes. A interiorização do ensino superior e a privatização do público. Goiânia: UFG, 2001.

FACULDADE DE FILOSOFIA, CIÊNCIAS E LETRAS DO VALE DO ITAJAÍ. FFCL. Catálogo do curso de Pedagogia - 1986/87. Itajaí, 1986. 
FAIRCLOUGH, Norma. Discurso e mudança social. Tradução Izabel Magalhães (Coord.). Brasília: Editora da UnB, 2001.

FREITAG, Bárbara. Escola, Estado \& Sociedade. 6. ed. São Paulo: Moraes, 1980.

FRIGOTTO, Gaudêncio. Educação e a crise do capitalismo real. São Paulo: Cortez, 1995.

FUNDAÇÃO EDUCACIONAL DE BLUMENAU. FURB. Faculdade de Filosofia, Ciências e Letras de Blumenau. Regimento Geral. Blumenau, 1968.

FUNDAÇÃO EDUCACIONAL DO SUL DE SANTA CATARINA. Estatuto. Tubarão, 1967.

GERMANO, José Willington. Estado militar e educação no Brasil (1964-1985). São Paulo: Cortez, 1993.

HAWERROTH, JolmarLuis. A expansão do ensino superior nas universidades do sistema fundacional catarinense. Florianópolis: Insular, 1999.

MORETTI, Serenito A. Movimento estudantil em Santa Catarina. Florianópolis: IOESC, 1984.

PREFEITURA MUNICIPAL DE CRICIÚMA. Anais, I' Seminário Pró Implantação do Ensino Superior na Região Sul Catarinense, Criciúma, 22 a 23 de julho de 1968.

ROSSI, Wagner. Capitalismo e educação: contribuição ao estudo crítico da economia da educação capitalista. 2. ed. São Paulo: Moraes, 1980.

SANTA CATARINA. Diagnóstico e Prognóstico da Situação Educacional. MEC/SEE/CEE/UDESC. Florianópolis, junho de 1971.

Diagnóstico e Prognóstico da Situação Educacional. MEC/SEE/CEE/ UDESC: Florianópolis, 1972.

. Plano Setorial de Educação. 1973-1976, v. 1.

Plano Setorial de Educação II. 1977-1980.

SANTOS, Sílvio Coelho dos. Educação e Desenvolvimento em Santa Catarina. Florianópolis: Editora da UFSC, 1968.

SAVIANI, Dermeval. Educação: do senso comum à consciência filosófica. 5. ed. São Paulo: Cortez; Autores Associados, 1985.

SILVA, Elizabeth Farias da.Ontogenia de uma universidade: a Universidade Federal de Santa Catarina (1962-1980). 2000. 291 f. Tese (Doutorado em Educação) - Universidade de São Paulo, São Paulo, 2000. 
SILVEIRA, José Carlos da.A gênese do ensino superior de Geografia em Santa Catarina: da Faculdade de Filosofia à Universidade Federal. Florianópolis, 2003.

UNIVERSIDADE DO EXTREMO SUL CATARINENSE. UNESC. Departamento de Pedagogia. Relatório do curso de Pedagogia. Criciúma, 1993.

VAHL, Teodoro R.A privatização do ensino superior no Brasil; causas e consequências. Florianópolis: UFSC; Lunardelli, 1980.

VELHO, Ricardo Scopel. 2003. 113 f. Ensino Superior em Santa Catarina: o público e o privado nas fundações educacionais. Dissertação (Mestrado em Sociologia Política) Universidade Federal de Santa Catarina, Florianópolis, 2003.

VIEIRA, Leida Maria Martins. UNIPLAC: a ideia de universidade como discurso de desenvolvimento. 2001. Dissertação (Mestrado em Sociologia Política) - Universidade Federal de Santa Catarina, Florianópolis, 2001.

Recebido em abril-2014

Aprovado em maio-2014

\footnotetext{
${ }^{\text {i }}$ Professora do Programa de Pós-Graduação em Educação - Universidade do Sul de Santa Catarina UNISUL
} 